\title{
INTELIGIBILIDAD Y CUALIDADES SENSIBLES: DE DESCARTES A BERKELEY O DE LA RESURRECCIÓN DE LAS CUALIDADES SECUNDARIAS*
}

JosÉ A. ROBLES

INSTITUTO DE INVESTIGACIONES FILOSÓFICAS

UNIVERSIDAD NACIONAL AUTÓNOMA DE MÉXICO

\section{Presentación}

Descartes, en su estudio del mundo natural, sigue la línea trazada por Galileo, al considerar que la mejor manera de hacer inteligible la sustancia material o res extensa es aplicarle la herramienta matemática y coincide con el pisano (o florentino, como a él le agradaba calificarse), igualmente, al excluir del mundo todas aquellas propiedades que no puedan sujetarse a dicho tratamiento matemático o, más precisamente, geométrico. En efecto, Galileo, en Il saggiatore, tiene este conocido pasaje:

Ahora digo que, cuando quiera que concibo cualquier sustancia material o corpórea, inmediatamente siento la necesidad de considerarla como limitada y

* Versiones anteriores del presente artículo las leí en 1996 (en el 400 aniversario del nacimiento de Descartes) en dos foros (internacionales) de homenaje; uno en Buenos Aires y otro en la ciudad de México, además de ya haberlo hecho en nuestro seminario del Área de historia de la filosfía en el Instituto de Investigaciones Filosóficas (UNAM); una presentación final de este trabajo tuvo lugar en Cáceres, en el I Congreso Iberoamericano de Filosofía (septiembre de 1998). En las tres primeras presentaciones, algunos de los vehementes cartesianos presentes formularon críticas, las que, según creo, me han permitido mejorar este escrito. Aquí deseo agradecer a todos los que participaron en las diversas presentaciones de mi trabajo pero, en particular a Carmen Silva, sus comentarios y su lectura detenida de este escrito; a Zuraya Monroy, sus atinadas sugerencias sobre aspectos de mis propuestas; a José de Teresa, su entusiasta defensa de mi tesis principal y, a Laura Benítez, su constante y decidido apoyo y sus observaciones, siempre pertinentes, a lo largo de todo mi trabajo, a pesar de estar en profundo desacuerdo con múltiples propuestas en el mismo; añado aquí mi agradecimiento a Víctor Rodríguez, de la Universidad de Córdoba (Argentina), quien comentó mi trabajo y me hizo adecuadas observaciones sobre el mismo. Quiero, finalmente, agradecer a Leiser Madanes su invitación a la reunión de Buenos Aires y a Manuel Reyes Mate la invitación para presentar, en Madrid, mi trabajo en la mesa de Metafísica y Ontología, coordinada por Juliana González; a ella, en particular, le agradezco haber sugerido que yo estuviera presente en su mesa 
como dotada de una u otra forma; como si fuera grande o pequeña con respecto a otras cosas y estando en un lugar específico en cualquier tiempo dado; como estando en movimiento o en reposo; como en contacto con o separada de algún otro cuerpo; como siendo, en número, una, unas cuantas o muchas. De estas condiciones no puedo separar ninguna sustancia mediante ningún esfuerzo de mi imaginación; pero mi mente no se siente obligada a traer, como una compañía obligada, el que sea blanca o roja, ácida o dulce, ruidosa o silenciosa o de un olor grato o desagradable. Sin los sentidos como nuestros guías, la razón o la imaginación, sin otro auxilio, probablemente nunca llegarían a cualidades como éstas. Por tanto, pienso que los sabores, los olores, los colores y demás, no son más que meros nombres con respecto al objeto en el que los situamos y que sólo residen en la conciencia. De aquí que si eliminásemos a la criatura viviente, se borrarían y aniquilarían todas estas cualidades. Pero, puesto que les hemos acordado nombres especiales, distintos de los de las otras cualidades reales mencionadas antes, deseamos creer que realmente existen como, de hecho, diferentes de aquéllas. (En [13], p. 274)

Ciertamente, la anterior es la propuesta que defenderá Descartes, y seguirá a Galileo, incluso en su manera de argumentar que los olores, colores, sabores y demás cualidades secundarias (en la terminología que hizo popular Locke), son asimilables a sensaciones claramente personales, subjetivas, como los dolores, cosquilleos, mareos, etc., que no atribuimos a ningún tipo de entidad externa (cuando nosotros las sentimos).

Tanto Galileo como Descartes llegan al resultado anterior, pues ambos rechazaban (como gran parte de sus antecesores inmediatos y de sus contemporáneos) las propuestas escolásticas y, con ellas, las aristotélicas, con respecto a la versión cualitativa que, de la física, daba el Estagirita (aun cuando Descartes acepta, matizada, la tesis aristotélica del pleno material, con respecto al espacio) y quieren ofrecer una descripción física del mundo que sea de una gran pureza matemática (geométrica) y, por ello, llegan al exceso ontológico contrario, a saber, rechazar todo [lo que ellos creen que es] lo cualitativo aristotélico.

Lo que puedo señalar, acerca de este proceso de pensamiento que generan Galileo y Descartes, es que éste se inicia con un pleno rechazo de la física aristotélica fuerte ( 0 , mejor, únicamente) cualitativa y se propone, según lo señalé, una visión puramente matemática o, más precisamente, geométrica, con respecto al tratamiento científico del mundo. Esta visión, entoncès, trae aparejada consigo, la tesis de que las cualidades no matematizables (en su momento), no son propiedades de los objetos del mundo material. La tesis, en este sentido, galileano-cartesiana, se propone como una visión, externalista, plenamente objetiva, que puede señalar sin lugar a dudas, cuáles propiedades pertenecen y cuáles no a los objetos materiales. Como parte de esta propuesta, Descartes mantiene que las propiedades matematizables (la 
extensión y sus modos, de manera esencial), conforman el mundo material, ajeno por completo al espíritu y al que éste no tiene un acceso cognoscitivc directo. Las propiedades que caen fuera del marco matemático (geométrico), se hacen un híbrido: surgen de la interacción entre cuerpos y espíritu y, finalmente, tal como los dolores o los sentimientos, serán catalogadas, por Descartes, como modos del espíritu.

En este escrito, compuesto básicamente de tres partes ampliaré, en la primera de ellas, la propuesta de Descartes que he descrito en las líneas anteriores; en segundo lugar, argumento, siguiendo una propuesta de HuygensLeibniz, que es imposible sostener la tesis cartesiana sobre la materia [materia que Malebranche, cartesiano heterodoxo, caracterizó como ininteligible], pues de tal propuesta se puede inferir la identidad del pleno [material] cartesiano con el espacio vacío y esto es una reductio ad absurdum de la tesis de Descartes.

Como una parte final, presento la visión, en gran medida opuesta a la galileano-cartesiana, del joven filósofo irlandés, George Berkeley, quien ya desde sus Comentarios filosóficos (redactados en 1707-1708; cuando tenía 23 años), encuentra que difícilmente puede existir o siquiera ser aceptable un mundo que, conforme a la descripción que del mismo dan los más hábiles filósofos de la época (Descartes, Locke, Malebranche), resulta, al menos, ser contradictorio, si no es que plenamente ininteligible. Su tesis central la podemos interpretar, a diferencia de la propuesta cartesiana, como una tesis más bien internalista, pues su autor concluye, guiado por consideraciones diferentes de las que tuvieron en mente Huygens y Leibniz, pero de manera muy cercana a ellos, que no podemos conocer y, menos aún, legislar, un mundo ajeno a la captación, esto es, al conocimiento del hombre, por lo que, por una parte, es absurdo postular la existencia de una materia ajena a nuestro alcance cognoscitivo y, así, Berkeley formula una propuesta, conforme a la cual, lo que sea el mundo sensorial depende, en gran medida [no totalmente, pues ese mundo es de creación divina], de la "interpretación" que hace el sujeto de lo que ante él se presenta: esse est percipi vel percipere y, a partir de esto, Berkeley rechaza la separación tajante (cartesiano-lockeana, como bien se sabe) entre las cualidades primarias y las secundarias, dándoles primacía a estas últimas sobre las primarias (para efectos tanto epistémicos como ónticos) y, de esta manera, sin recaer en propuestas de tesis de física cualitativa aristotélica, Berkeley muestra que las cualidades secundarias, por las que conocemos el mundo, son las que nos dan la pauta para el tratamiento físico-matemático que Descartes pretendía aplicarle.

Desde la perspectiva berkeleyana, el mundo real consta, para el ser humano, tanto de cualidades primarias como de secundarias, ninguna de ellas tiene primacía con respecto a la caracterización del mundo sensorial. Así, 
para Berkeley, las llamadas cualidades primarias están sujetas a las mismas contingencias y eventualidades que las que sólo se atribuían a las secundarias. Ciertamente, las cualidades se pueden distinguir, pero no separar.

Ahora, pues, sólo deseo bosquejar la parte de la historia de la filosofía que se desenvuelve del año 1637, en el que Descartes publica su Dióptrica (o, quizás, habría que tomar en cuenta el año de 1629 en el que, a la edad de 33 años, escribió El mundo o tratado de la luz), hasta el de 1710, en el que Berkeley publica su Tratado sobre los principios del conocimiento humano, y que gira sobre el estatus ontológico de las cualidades sensibles o secundarias, a diferencia de las mecánico-geométricas (para usar una feliz expresión de Laura Benítez) o primarias (ampliadas). En mi bosquejo, también tendrá que figurar la relación que las ideas (palabra que fue tan abusivamente usada en los siglos xvi y xviI) mantuvieron con el mundo de objetos materiales (res extensa cartesiana) y la mente o el espíritu (res cogitans, para seguir con los apelativos de Descartes).

Aquí quisiera añadir lo siguiente. La propuesta de Berkeley la podemos entender en el sentido de rechazar que, sólo por el carácter matematizable de las cualidades primarias habrá que darles un estatus óntico diferente (y superior) del de las llamadas cualidades secundarias. Lo que la crítica de Berkeley pone de manifiesto es que las cualidades sensibles de los objetos tienen diferentes pesos, pero no diferente estatus óntico, de acuerdo con la perspectiva desde la que queramos contemplar el mundo: la física cartesiana, que deja de lado los aspectos no matematizables de la realidad sensible, no les concede ninguna importancia a las cualidades secundarias. Empero, desde alguna otra perspectiva, las cualidades secundarias pueden tener mayor importancia que las primarias pero, no por esto, se erigirán aquéllas como las cualidades de los objetos del mundo perceptual. Así pues, Berkeley les concede un estatus óntico igual tanto a primarias como a secundarias, aun cuando esta situación pueda variar si se las considera desde perspectivas diversas.

Por otra parte, y para concluir con estas observaciones introductorias, considero que el análisis de las propuestas de Berkeley nos permitirá subrayar el hecho de que, dentro de su perspectiva, y como él mismo llegó a decirlo en diversas ocasiones, las cosas no se han hecho ideas sino, más bien, las ideas se hän hecho cosas. ${ }^{1}$ Asimismo, será posible sostener que el mundo berkeleyano carece del elemento generador del escepticismo, como lo era la

1 Acerca de esta propuesta berkeleyana cfr. [5], diálogo 3 (p. 244). Por otra parte, Berkeley rechaza la propuesta de algunos autores de la época de que las ideas sean modos del espíritu; en su uso de "idea", una idea es algo ajeno al espíritu, que éste capta o aprende como idea, esto es, como algo ajeno al espíritu mismo; acerca de su rechazo del subjetivismo o solipsismo de su posición cfr. CF 807 (en [3]), [4] §49, [5], diálogo 3, pp. 249 y ss. 
sustancia material, que Descartes postula y que aceptan, entre otros, Locke y Malebranche.

\section{René Descartes (1596-1650)}

Son varias las propuestas de Descartes que me interesa presentar en este escrito, lo que haré de la manera más breve y precisa posible, para luego expresar algunos comentarios sobre las mismas y pasar, por último, a considerar, en parte, las reacciones que, sobre tales propuestas cartesianas, formularan John Locke, Nicholas Malebranche y, de manera central, George Berkeley.

\section{2a. Metafísica cartesiana}

Acerca de las tesis centrales de Descartes no necesito detenerme demasiado, por ser de todos bien conocidas, pero sí me interesa precisar algunos detalles sobre la caracterización de la res extensa y de la relación cognoscitiva del sujeto con respecto al mur.do material. Por otra parte, daré aquí por supuesto que Descartes logra convencernos (cosa que no sucedió con Malebranche, por ejemplo) de que, apoyándonos en la infinita bondad de Dios, tenemos una prueba de la existencia de un mundo material, aun cuando no conozcamos los detalles del mismo, esto es, gracias al apoyo en la Divinidad sabemos que hay un mundo material, extenso y, por lo mismo, sujeto a las leyes geométricas, aun cuando, más allá de esto, no sepamos (con mayor detalle) cómo sea.

La tesis cartesiana central, de sobra conocida, es su propuesta dualista, esto es, su radical separación de espíritu y materia: ${ }^{2}$ por una parte tenemos la res cogitans, inextensa, cuyo atributo esencial es el pensamiento y, por otra, la res extensa, material e inerte. Fuera del ser y de la duración, condiciones de posibilidad de existencia de todos los seres creados, las entidades pensantes son, en cuanto a atributos propios, totalmente ajenas a las entidades materiales y viceversa.

\section{2b. Mundo físico: cuerpos inertes y representación eidética}

Conforme a su propuesta ontológica, Descartes sostiene que los objetos materiales tienen sólo las cualidades geométricas propias de la extensión, esto es, del espacio: largo, ancho y profundo. Lo que aquí me interesa señalar es que (según se verá más adelante), Descartes, por una parte, rechaza la existencia de un espacio vacío y, por otra, no desea comprometerse con

${ }^{2}$ Cfr. para una incisiva formulación de la diferencia, el tránsito de la 2a. a la 3a. meditaciones, en [9] VII 30-35 (latín), LX 25-28 (francés). 
la complejidad (y oscuridad, desde su perspectiva) de una metafísica de formas sustanciales, por lo que rechazará la distinción materia-forma para fundar su física.

Lo que Descartes alega es que si algunos pensadores, antecesores y contemporáneos suyos (entre ellos Patrizi, Gassendi y Herny More), consideraron que el espacio vacío era una magnitud tridimensional, él mantiene que esa supuesta caracterización, nada describe. o, lo que logra, es tan sólo "apuntar" a un no ser (éste sería un paradigma de lo que Descartes mismo denominó "falsedad material"3) pues, si quienes usan la expresión "espacio vacío", pretenden aludir a una supuesta idea que se refiere a alguna entidad exterior, conforme a Descartes, no hay nada que pueda ser el referente de la misma y, por esta razón, porque lo que no es, la nada, no puede tener atributos de ninguna especie, "el espacio vacío", dado que no existe, no puede tener dimensiones. Acerca de la identificación entre espacio vacío y nada, Descartes es fuertemente aristotélico.

Por otra parte, con respecto a su segunda meta, declaradamente antiaristotélica, señala (entre otros lugares) en Principios IV $\S 201$, in fine (pp. 219-220), que cualquier persona dotada de razón encontrará que es mucho mejor tomar en cuenta sus propuestas. .

y dar razón, por este medio, de todo lo que está en la naturaleza, tal como lo he intentado hacer en este tratado, que dar razón de las mismas cosas, inventando no se qué otras que no tienen relación alguna con nuestras sensaciones, como lo son la materia prima, las formas sustanciales y todo ese gran arsenal de cualidades que muchos tienen la costumbre de suponer, cada una de las cuales puede conocerse, cada vez de forma más dificil que las cosas que se pretenden explicar por su medio. ${ }^{4}$

3 Sobre esto, cfr. Meditaciones [9] VII, 43-44 (latín); IX 43 (francés). En este lugar, Descartes dice:

"Pues aun cuando yo hubiese señalado que sólo en los juicios es donde puedo encontrar la verdadera falsedad formal, sin embargo, en las ideas se puede encontrar cierta falsedad material, a saber, cuando ellas representan lo que no es como si fuese algo [...] si ellas son falsas, es decir, si presentan cosas que para nada son, la luz natural me hace saber que ellas proceden de la nada, esto es, que ellas no son sino porque algo le falta a mi naturaleza y porque ella no es totalmente perfecta. Y, si las ideas son verdaderas sin embargo, debido a que me muestran [qui tamen tam parum realitas mihi exhibent] que, incluso yo, no puedo discernir claramente del no ser, la cosa representada, no veo ninguna razón por la que no las pueda producir yo mismo y que no sea yo su autor."

4 Tras haber dado su versión (en [10] II §7) de la explicación de la rarefacción de los cuerpos, aire y agua, entre ellos, apelando a los poros que se supone que tienen y a la penetración, por éstos, de la materia más sutil, invisible para nosotros, al igual que los poros por la que penetra: esta materia muy sutil, al penetrar en un cuerpo (y éste puede serlo el aire o el agua según lo señalé), lo llena y lo enrarece. Descartes, tras alabar su explicación y señalar que la misma debe aceptarse porque "es imposible concebirlo de otra manera" - recordemos 
que, en el texto principal, Descartes también insiste en subrayar las bondades de su manera de explicar las cosas - pasa, en el §8, a decirnos lo que realmente constituye un cuerpo. Y, así comienza explicando que:

"la magnitud no difiere de lo que es grande y, el número, de lo que es enumerado, sino sólo en nuestro pensamiento, es decir, que aun cuando pudiésemos pensar en lo que es la naturaleza de una cosa extensa comprendida en un espacio de diez pies, sin cuidarnos de esta medida de diez pies, a causa de que esta cosa es de la misma naturaleza, en cada una de sus partes, como en la totalidad y que pudiésemos pensar en el número diez o en una magnitud continua de diez pies, sin pensar en tal cosa, a causa de que la idea que tenemos del número diez es la misma, sea que considerásemos un número de diez pies o alguna otra decena y que, incluso, pudiésemos concebir una magnitud continua de diez pies, sin reflexionar sobre tal o cual cosa, aun cuando no pudiésemos concebirla sin ninguna extensión, sin embargo es evidente que no podríamos eliminar ninguna parte de tal magnitud o de tal extensión, que no eliminase, por el mismo medio, otro tanto de la cosa y, recíprocamente, que no se podría eliminar de la cosa sin que se quitase, por el mismo medio, otro tanto de la magnitud o de la extensión".

En el $\S 9$, Descartes nos dice que:

"Si algunos se expresan de manera distinta sobre este tema creo, sin embargo, que no concebirán algo distinto de lo que acabo de decir pues, cuando distinguen la sustancia de la extensión y de la magnitud o no entienden nada por la palabra sustancia o tan sólo forman en su espíritu una idea confusa de la sustancia inmaterial que falsamente atribuyen a la sustancia material, que denominan accidente, de manera tan impropia, que es fácil saber que sus palabras no guardan ninguna relación con sus pensamientos."

Finalmente, en el $\S 10$, Descartes vuelve a subrayar su tesis acerca de la identidad de la magnitud y de la cosa extensa:

"El espacio o el lugar interior y el cuerpo comprendido en este espacio, no son diferentes sino en nuestro pensamiento; pues, en efecto, la misma extensión que constituye el espacio en largo, ancho y profundo, constituye el cuerpo y la diferencia que hay entre ellos no consiste sino en que nosotros le atribuimos al cuerpo una extensión particular, la que concebimos que cambia de lugar con él, todas y cada una de las veces que es transportado y que nosotros le atribuimos al espacio una [extensión] tan general y tan vaga que, tras haber quitado de cierto espacio el cuerpo que lo ocupaba, no pensamos que transportamos, también, la extensión de este espacio, a causa de que nos parece que la misma extensión siempre permanece ahí mientras tenga la misma magnitud y la misma figura y que no ha cambiado de situación con respecto a los cuerpos externos por los cuales la determinamos."

El §11 es importante porque, en él, Descartes hace explícita la naturaleza del cuerpo, al despojarlo de todos los elementos (apariencias) que nos engañan y nos hacen pensar que espacio y cuerpo son por completo diferentes (véase, asimismo [9] II, §4) El argumento que nos presenta Descartes es el mismo que, en la "meditación II", al analizar un trozo de cera, lo llevó a la convicción de que la naturaleza del cuerpo, de la sustancia material era la de ser extensa (res extensa):

"Pero será fácil saber que la misma extensión, que constituye la naturaleza del cuerpo, constituye, también la naturaleza del espacio, de manera que, entre ellos, no difieren sino como la naturaleza del género o la de la especie difiere de la naturaleza del individuo si, para mejor discernir cuál es la verdadera idea que tenemos del cuerpo, tomamos como ejemplo una piedra y le quitamos todo lo que sabemos que para nada pertenece a la naturaleza del cuerpo. Así 
Una vez convencido de lo anterior, Descartes hace una maniobra verbal, con la que pretende, tanto recobrar el espacio, como evitar las complicaciones escolástico-aristotélicas y, con ello, dar cuenta de las propiedades físicas del mundo material. Para lograr esto, Descartes concluye que la materia es espacio (y a la inversa), esto es, identifica materia y espacio y, con ello, elimina el vacío, la nada, y puede hablar de tridimensionalidad sustancial sin, por otra parte, tener que suponer un sustrato o una materia prima.

Así pues, lo que hace Descartes, nuevamente de manera aristotélica, es no tomar el espacio vacío y hacerlo el recipiente de la materia (antecedentes de esta propuesta serían los atomistas clásicos, Leucipo y Demócrito (ambos ca. 460-370), Filópono (490-566), Patrizi (1529-1597), Gassendi (15921655) y Henry More (1614-1687)), pues esto sería tanto como decir, desde la perspectiva aristotélico-cartesiana, que lo que no es, el vacío, es recipiente de lo que es, la materia, lo cual, para Descartes, sería una flagrante contradicción. 5

Tampoco su propuesta es, según lo he señalado, la de suponer un sustrato material (la materia prima o materia informe aristotélica) y luego hacer que

pues, quitémosle, primeramente la dureza [...] quitémosle, también el color [...] quitémosle el peso [...] quitémosle el frío, el calor y todas las otras cualidades de ese género, porque para nada pensamos que ellas estén en la piedra o que esta piedra cambia de naturaleza porque nos parece o bien caliente o bien fría. Tras haber examinado así esta piedra encontraremos que la verdadera idea que de ella tenemos consiste sólo en que apercibimos distintamente que ella es una sustancia extendida en largo, ancho y profundo; ahora bien, esto mismo está comprendido en la idea que tenemos del espacio, no solamente del que está lleno de cuerpo, sino también del que denominamos vacio".

5 Para evitar esta fatal identificación, plenamente aristotélica, entre espacio vacío y nada, Francesco Patrizi da Cherso, a quien luego seguirá Pierre Gassendi, señala que el espacio vacio no cae bajo ninguna de las categorías aristotélicas: no es sustancia, no es atributo pero, de esto, no se sigue que sea nada. El espacio vacío tiene ser, de alguna manera. Finalmente, Patrizi llena su espacio de luz (lumen, emanación de la lux prima); Gassendi lo mantiene vacío y coeterno con Dios, aun cuando con características plenamente negativas. Ambos autores interpretan el espacio vacío como condición de posibilidad de la existencia de los cuerpos. Así pues, a pesar de su afán de separarse lo más posible de las doctrinas del Estagirita, Descartes no logra desembarazarse plenamente de ellas.

Acerca de la relación, a este respecto, entre Gassendi y Descartes, Koyré (en [15], p. 309) nos dice lo siguiente:

'Al 'plenismo' cartesiano, Gassendi le opone resueltamente la existencia de los 'átomos' y del 'vacío', pero no se limita a eso. Desde 1646, ataca los mismos fundamentos de la ontología tradicional que Descartes, quizás sin darse cuenta de ello, había heredado de Aristóteles y que lo llevan como a este último, a la metafísica de sustancia y atributos. Pero, objeta Gassendi ya en sus Animadversiones in decimum librum Diogenis Laertii* [* Las Animadversiones se imprimieron hasta 1649 , pero fueron escritas antes de $1646 .$. ], ¿es legítima esta división? De hecho, 'ni el lugar ni el tiempo son sustancia ni accidente y, no obstante, son algo y no nada; justamente son el lugar y el tiempo de todas las sustancias y de todos los accidentes' "+ [ + cfr. Animadversiones, p. 614 (ed. de 1649)]. 
la forma, la tridimensionalidad, se impusiese a esa materia. Ya hemos visto la opinión que Descartes tenía con respecto a esta tesis.

Así pues, lo que hace Descartes es identificar materia y forma (esto es, extensión) y, con ello, tiene un mundo espacial en el que no hay (ni puede haber) vacío alguno, no hay (ni puede haber) ningún resquicio carente de sustancia, de materia. Lo que Descartes logra, con esto, es tener una extensión material uniforme la que, según lo argumentaré más adelante, para nada se distingue del espacio vacío.

Hasta aquí podemos decir que, si el deseo de Descartes era eliminar la insustancialidad del espacio vacío, lo logra diciendo que no er vacio sino que es materia; si no quiere sustratos o formas sustanciales, se deshace de ellos diciendo que la materia no es sustrato (para la forma), sino que es espacio (esto es, se pierde la distinción entre sustrato y forma). Así, con dos énfasis distintos en la formulación de su tesis, parece que se libra de dos enemigos serios para lograr una propuesta ontológica respetable.

De su identificación, materia-extensión, Descartes considera que claramente se infiere que los objetos materiales, esto es, porciones diferenciadas (en caso de que esto pudiera darse) de materia, tienen las cualidades de la extensión: figura y volumen, además del movimiento con el que Dios dotó, en su creación, las partículas de materia que forman tales objetos y, sobre esta base, tiene que explicar la presencia, en nuestros conceptos, de (ideas de) cualidades tales como las secundarias. ${ }^{6}$

6 Aquí vale la pena anotar que muy bien Descartes puede decir que Dios puso en movimiento las partículas de materia; pero, a esto, se le puede enfrentar una intuición diferente, para la cual, lo difícil es saber cómo puede efectuarse dicho movimiento si no hay ningún espacio independiente, a través del cual, pueda aquél llevarse a cabo (esto es algo que el mismo Aristóteles señala para luego rechazarlo, en [1] 4. 7. 214a 22-26, donde leemos: "Según ellos [los partidarios de la realidad independiente del lugar], la causa del movimiento es el vacío, como aquello en lo cual el movimiento se produce; ahora bien, es por algo como esto que algunos afirman la existencia del vacío"). Dicho de otra manera: conforme a esta intuición, enfrentada a la cartesiano-aristotélica, si todo y el único espacio que Descartes (Aristóteles) acepta en su universo, es el de los cuerpos, pues no hay materia sin espacio ni espacio sin materia (muy similar a la relación materia-forma de la metafísica aristotélica, heredada, luego, por la Escolástica, bajo cuya influencia estudió Descartes en La Flèche), entonces, no hay espacio vacío; esto lo reconoce el mismo Descartes (y Aristóteles rechaza, igualmente, su posibilidad), pero la consecuencia de hacerlo es que ningún cuerpo (en caso de que pudiera haberlo) puede ocupar el espacio de otro; pero, si esto es así, (i) no es posible que un cuerpo se deslice hacia otro 'lugar' (pues, bajo estas circunstancias, no parece poder haber algo así como un lugar) y, finalmente, se concluiría que (ii) ino puede haber cuerpos!, como trozos diferenciados y separables de materia.

Ahora es posible traer a colación dos lecturas, contemporáneas de los textos de Descartes que confluyen en la conclusión (ii). Primeramente, presento la propuesta de Bernard Williams:

"El universo físico, para Descartes, consiste en una cosa infinitamente extensa, homogénea y tridimensional (Principios II $\S \S 21,22$; 'indefinido' es la palabra que el propio Descartes prefiere 
para el tipo de infinitud negativa en cuestión). No tiene y no puede tener ningún hueco; se sigue que no puede haber ninguna pluraliad de mundos y que cualquier cosa extensa que hay es una parte o región de la única cosa extensa. No hay, además, átomos últimos o partes de materia que sean 'indivisibles' por su propia naturaleza (Principios II, $\$ 20$ ) -la materia, en la concepción cartesiana, tiene necesariamente la propiedad geométrica de ser continua." (En [25], p. 253 (inglés) y p. 254 (español))

Aqui es interesante señalar que, a Williams, en su descripción, le faltó señalar que a la extensión continua, material, cartesiana, también le corresponde el atributo del isotropismo pues, por una parte, en ella (vista tan sólo geométricamente) no puede darse el movimiento y, por tanto, tomando en cuenta las cualidades geométricas (únicas) que le son propias, no hay manera de distinguir partes.

Esta conclusión, aun cuando no de manera explícita, la presenta Kenny en el siguiente pasaje:

"Descartes dice que el mundo está compuesto de cuerpos de tres tamaños diferentes. ¿Cómo han de distinguirse estos cuerpos? ¿Qué son las cosas que tienen tamaños? Para que algo tenga tamaño debe tener los límites de un cuerpo único (o de una parte de la materia); eso [lo que tiene taman̄o] no pueden ser cualesquiera propiedades geométricas, la extensión tridimensional se extiende uniformemente hasta el infinito." (En [14], p. 214)

Estas dos últimas citas figuran (en inglés) en [2], p. 109.

Por otra parte, la conclusión (i), anterior, la sacó, en el siglo w, Juan Filópono de Alejandría, al proponer, en su comentario a la Física de Aristóteles, que había que suponer el espacio externo (y vacio) para poder dar cuenta del movimiento. La tesis de Filópono es por demás interesante, ya que propone el espacio como continente de todos los existentes en el universo aristotélico y, aun cuando señala que, por su naturaleza podría estar vacio, de hecho no lo está. Filópono formula, luego, su propuesta de otra manera, a saber, subrayando que cuerpo y espacio vacio están en una relación más estrecha, como lo están la materia y la forma dentro de la propuesta metafísica de Aristóteles (quien desee conocer los argumentos en los que apoya Filópono ésta y otras propuestas más, podrá leer [12] con provecho). La última observación de Filópono, me sugirió una posible motivación del rechazo que hace Aristóteles del espacio vacío y ésta sería que, un espacio así, le sugiere, fuertemente, la existencia de una forma sin sustancia, sin contenido y por ello, dice que parece "más bien una carencia que un ser" (esto lo señala en [1] 4. 8. 215a 11-15: "pues en la nada no hay ninguna diferencia, al igual que en el no ser y el vacío, parece ser un no ser y una privación. . . "; así pues, la propuesta metafísica fundamentaría la propuesta física y esto mismo se podría decir, igualmente, de Descartes). Pero, volviendo a Filópono, lo importante de su propuesta del espacio vacío, es que éste es distinto e independiente del espacio-atributo-de-los-cuerpos y, teniendo esto en cuenta, se puede ya pensar (desde esta perspectiva vacuista, que se propone como algo más natural que la propuesta plenista) en un posible deslizamiento de un cuerpo a lo largo de algo diferente de él mismo y/o de otros cuerpos. O, para decirlo con Leibniz " $y$, a mi juicio, la movilidad misma o la $\dot{\alpha} \nu \pi \imath T \breve{u} \pi \dot{\alpha} \alpha$ no se puede entender a partir de la mera extensión, sino a partir del sujeto de la extensión, que no constituye sólo el lugar, sino que, además, lo llena" ( $c f r$ infra el epígrafe al §2d.); y esta propuesta leibniziana va, precisamente, en contra del repudio aristotélico-cartesiano del espacio vacío.

Quien sostenga la intuición vacuista que he presentado, alegaría que la confusión, tanto de Aristóteles como de Descartes, fue la de pensar que, una vez garantizado el espacio de los cuerpos, ya éstos podrían moverse; pero, para este movimiento, se tienen dos opciones: 
A este respecto, Descartes rechaza la explicación aceptada en la época, de que los objetos físicos envían imágenes pictóricas a nuestro aparato visual (tesis que sustuvieron Alhazen y Witelo, ${ }^{7}$ antes de decirlo Kepler).

La explicación la da en términos de organización, movimiento y choque de partículas de materia en las terminaciones nerviosas en nuestro cuerpo; de esta manera se forma una impresión en la glándula pineal y el espíritu se hace consciente de la misma, aun cuando, ahora, ya no se apela a la acción mecánica causal. Así, lo que tenemos, en el caso cartesiano, como conocimiento del mundo sensible, es una tesis de percepción representativa, aun cuando la representación no se asume (como sí lo hace Locke en el caso de las ideas y las cualidades primarias) como una semejanza entre el percepto y el objeto, pues éste carece (en la visión científica del mismo) de las cualidades secundarias. Así pues, lo que tiene el espíritu ante sí, es una "interpretación" del producto de la interacción: una idea del mundo sensible, en la que están presentes tanto cualidades primarias como secundarias y, de esta forma, a la manera del lienzo que presenta la pintura, ante el espíritu se hace patente la extensión.

Sin embargo, si sólo nos quedamos con estas características del mundo, desde la perspectiva científica, lo que tenemos es sólo una extensión tridimensional, homogénea, isotrópica, esto es, las propiedades geométricas del mundo, que para nada propician la distinción entre objetos y, por esto, el pleno material para nada se distingue del espacio vacío, aun cuando ahora se nos diga que es material. O bien, dicho de otra manera, en el

i) un cuerpo se mueve en su propio espacio; pero esto es absurdo, pues un cuerpo no se traslada moviéndose en su propio espacio y, por otra parte, es difícil saber qué quiera decir esto;

ii) un cuerpo se mueve a lo largo de un espacio externo, vacio; es claro lo que esta propuesta quiere decir, pero tanto Aristóteles como Descartes se negaron a aceptar un espacio externo; pero si, por i) no es posible el movimiento (a menos que sea circular — por ejemplo, el de una esfera girando alrededor de uno de sus ejes-, como lo reconocieron tanto Aristóteles como Descartes, aun cuando el primero nos habla de movimiento natural en línea recta, para los elementos en la esfera sublunar) y ellos no aceptan ii), entonces, conforme a su esquema, ino puede haber movimiento!

7 Vitellio (o Witelo, de nombre real Erasmo Ciolek, 1210-1285) fue un físico matemático, de origen silesio (en Polonia), quien escribió una obra de publicación póstuma (Vitellionis perspectiva, publicada en 1533) en la que recogía los trabajos de Ptolomeo y Alhazen (Ibn Al Haythan, 965-1039). En 1572, Risner, en Basilea, publicó estudios de óptica de Vitellio (Opticæ thesaurus) al editar la óptica de Alhazen (traducida al latín con el nombre de De aspectibus, también conocida como Perspectiva o De visu).

Kepler escribió su Ad Vitellionem paralipomena, quibus astronomiæ pars optica traditur (Adiciones a Vitellio, en la que se trata la parte óptica de la astronomía, 1604), obra en la que, según lo señala Caspar, Kepler usa la obra de Vitellio como punto de partida para llevar a cabo una investigación a fondo y reúne todo lo que sabía de óptica "con lo que el autor, para ser francos", continúa Caspar, "obtuvo el epíteto, universalmente reconocido, de fundador de la óptica moderna" (en [6] p. 144). 
mundo cartesiano tenemos todas las propiedades del espacio vacío (con una sola excepción) las que, en esencia, son las propiedades de la materia. La excepción, como es obvio, es que, del espacio vacío se dice que es penetrable, mas no así del pleno material; pero, a pesar de esta notoria diferencia, tanto en el caso del vacío como en el del pleno, podemos mantener la absoluta inmovilidad, ya que, en el vacío, no hay algo que se mueva (pues ahí nada tangible hay) y, por otra parte, no hay forma de cambiar de lugar porciones de espacio, pues no hay diferencia entre dos "porciones" cualesquiera del mismo, observación que ya había formulado Patrizi y que luego repetirá Newton; en el caso del pleno, la plenitud misma, tomada en serio, impide cualquier movimiento (según lo había señalado Parménides y, luego de él, Meliso y los eléatas en general) y la identificación materia-extensión impide que haya cualquier diferencia, por lo que de esto se sigue, al igual que en el caso del espacio vacío, que la isotropía impide dar cuenta de cualquier tipo de movimiento. Entonces icómo podemos distinguir algo, en esta extensión, que nos muestre que es un pleno material y no un espacio vacío?

\section{2c. Sobre una analogia lingüística fallida}

Para explicar nuestro conocimiento del mundo material, Descartes esboza una analogía lingüística, la cual señala que, así como las palabras, sin tener parecido (semejanza) con aquello a lo que se refieren, logran despertar en nosotros su idea, así también las imágenes que tenemos del mundo exterior logran despertar en nosotros alguna supuesta idea de-la existencia de algo a lo que, de alguna manera por precisar, corresponde la idea que brota en nosotros. ${ }^{8}$

8 La propuesta de Descartes es la siguiente:

'Vos bien sabeis que, sin tener semejanza alguna con las cosas que significan, las palabras no dejan por ello, de hacérnoslas concebir y, con frecuencia, incluso sin que prestemos atención a los sonidos de las palabras ni sus sílabas, de manera que puede suceder que, tras haber oído un discurso, cuyo sentido hemos comprendido muy bien, nosotros no podamos decir en qué lengua fue dicho.

Ahora bien, si las palabras, que nada significan sino por la convención de los humanos, bastan para hacernos concebir cosas, con las que no tienen ninguna semejanza, ¿por qué la naturaleza no podría, también, haber establecido cierto signo que nos hiciese tener la sensación [sentiment] de la luz, aun cuando este signo no tuviese nada, en sí mismo, que se asemejase a esa sensación? Y, ¿no es así que ella ha establecido las risas y las lágrimas para hacernos leer la alegría y la tristeza en la cara de los hombres?" (En [7], p. 4)

Zuraya Monroy, en su lúcida propuesta de interpretacion semántica, de pasajes clave de la epistemología cartesiana (en [24], p. 186), presenta un pasaje de la Dióptrica (además del que acabo de presentar, de $E l$ mundo) en el que Descartes hace un primer intento de formulación 
La exclusión, por parte de Descartes, de las cualidades sensibles (secundarias) como propias del objeto real de conocimiento, quiere poner de manifiesto la necesidad de atribuirle al mundo propiedades de las que podamos dar una explicación lo más clara posible. Ciertamente, si de las propiedades del mundo podemos dar una explicación matemática, esto es, geométrica, daremos, desde el punto de vista cartesiano, la mejor explicación, la menos sujeta a cuestionamientos, la explicación que, con la mayor claridad y distinción, nos hará inteligible el mundo físico, el mundo, en cierto sentido, por completo ajeno al espíritu. El problema para Descartes, según veremos, es el de que no podrá alcanzar las figuras y los cuerpos materiales a los que desea aplicar la más clara y precisa de las ciencias: tantas trabas pone en su ruta para obtener la certeza, que una de ellas es, precisamente, la de cerrarse el camino para llegar al conocimiento del que considera el mundo real, auténtico, que las ideas pretenden comunicarle.

Ciertamente, prima facie, la analogía no cumple con su cometido, pues no tenemos ante nosotros los dos términos de la relación, esto es, la idea y lo que ésta se supone que representa, como si tenemos, ante nosotros, la palabra y aquello a lo que ésta se reficre. El problema que aquí surge es, en cierto sentido, similar al que detecta Berkeley en Locke, cuando éste afirma que hay una semejanza entre las cualidades primarias y sus ideas, lo que podríamos mantener sólo en el caso de tener ante nosotros ambos términos de la relación. ${ }^{9}$ En el caso cartesiano, hay un signo, las ideas, que pretenden (según Descartes) referirse a lo ajeno al espíritu, a los objetos materiales,

de la analogía entre palabra-referencia y perceptos-objeto material, en los siguientes términos (presento un pasaje más amplio que el que presenta Zuraya):

"Es preciso, además de eso, cuidarse de no suponer, tal como lo hacen comúnmente nuestros filósofos que, para percibir [pour sentir], el alma tiene necesidad de contemplar algunas imágenes que le sean enviadas por los objetos hasta el cerebro 0 , al menos, es preciso concebir, la naturaleza de esas imágenes, de manera distinta de como ellos lo hacen; pues, mientras no consideren en ellas otra cosa sino que deben ser semejantes a los objetos que representan, es imposible que nos muestren cómo pueden ellas estar formadas por esos objetos, ser recibidas por los órganos de los sentidos externos y transmitidas por los nervios hasta el cerebro. $Y$ no tienen razón alguna para suponer eso, sino que, al ver que nuestro pensamiento puede, fácilmente, ser estimulado por un cuadro a concebir el objeto que en él está pintado, les ha parecido que debe ser lo mismo para concebir aquello que toca nuestros sentidos, mediante pequeños cuadros que se formasen en nuestra cabeza, en tanto que nosotros debemos considerar que hay muchas otras cosas, además de las imágenes, que pueden estimular nuestro pensamiento; como, por ejemplo, los signos y las palabras, que no se asemejan, de ninguna manera, a las cosas que significan..." (En [8], p. 112)

9 Locke, en [19] II, viii, 7, se expresa a la manera cartesiana, en el sentido de señalar que no hay que suponer que las ideas nos presentan las cosas tal camo éstas son e incluso emplea el símil semántico cartesiano: las ideas, como las palabras, no tienen que parecerse a las cosas que representan para traérnoslas a la mente; sin embargo, en II, viii, 9, précisa más su propuesta, señalando que las ideas de las cualidades primarias sí son similares a las 
pero de éstos no sabemos más que lo que los signos nos presentan y lo que Descartes señala es que tal presentación no es veraz en tanto que nos muestra ideas sensibles $\mathrm{y}$, ciertamente, la presentación necesita de ellas para que nosotros podamos percibirlas. Así pues, nuestro mundo sensorial, el único presente ante nosotros, nos muestra siempre cualidades sensibles.

Sin embargo, en este mundo sensible, descubrimos aspectos del mismo, según nos lo enseñaron los griegos, a los que podemos aplicar medidas y teoremas geométricos, pero sólo de manera aproximada (conforme nos lo enseñó Platón) y esto, entre otras cosas, mueve a Descartes a eliminar las engañosas y engorrosas cualidades secundarias para hablarnos del mundo (científico) real y verdadero que carece de tales cualidades, propias sólo para que criaturas finitas, como nosotros, podamos movernos sin demasiados peligros en él.

No obstante, si queremos conocer las verdaderas propiedades geométricas del mundo, tenemos que llevar a cabo cálculos, mediciones y aplicaciones sobre el mundo de las presentaciones sensoriales y, entonces, siempre nos podemos preguntar cómo es que las medidas y consideraciones geométricas, que aplicamos a las presentaciones sensoriales del mundo, han de aplicarse a las entidades materiales mismas. De esto parece surgir un dilema, o hay una (casi) identidad entre el mundo sensible cartesiano y su mundo material (que es la intuición que de esto tuvo Locke) y, entonces, parece por completo innecesaria la separación de mundos, el de sentido común y el científico, o no será posible que tengamos conocimiento alguno de este último pero, en-

cualidades en las cosas, aun cuando las ideas de cualidades secundarias no representan nada en la cosa, en el objeto material.

Acerca de la propuesta lockeana, Berkeley formula dos tipos de crítica: un caso del primero, figura en [4] $\S 9$ (Berkeley vuelve a emplearlo en [5], diálogo 1, p. 206), en donde, luego de señalar que "Algunos formulan una distinción entre cualidades primarias y secundarias" y de expresar la tesis de Locke (sin mencionarlo) de la semejanza entre las ideas de las cualidades primarias y las cualidades mismas, argumenta que la propuesta es contradictoria, pues pretende afirmar una semejanza entre cosas que son totalmente ajenas, esto es, las ideas, como algo que tiene relación con el espíritu y, la materia, como algo ajeno al espíritu; en concreto, Berkeley señala que no puede haber semejanza entre lo perceptible y lo que es imperceptible en principio. Una crítica diferente, en la que no se le achaca, de manera expresa, una contradicción a la propuesta lockeana (pero que, finalmente, es equivalente a la primera), figura en [5] (diálogo 3, p. 246), en donde Berkeley señala que, para poder establecer una relación de semejanza, es preciso tener acceso a los đos términos de la relación. La propuesta la hace Filonús, el portavoz de Berkeley, de la siguiente manera:

"Filonús: ¿Es tu opinión, Hylas, que las ideas que percibimos por nuestros sentidos no son las cosas mismas sino imágenes o copias de ellas? Por lo tanto, nuestro conocimiento no es más real sino en tanto que las ideas sean las representaciones veraces de esos originales. Pero, como los supuestos originales son en sí mismos desconocidos, es imposible saber hasta dónde se asemejan a ellos nuestras ideas o si es que siquiera se les asemejan. Por tanto, no podemos estar seguros de tener algún conocimiento real." 
tonces, aquí parece innecesario, por absurdo, suponerlo (que es la intuición que de esto tuvo Berkeley). ${ }^{10}$.

Sin embargo, por una parte, Descartes considera que puede confiar en que existe un mundo externo pues, en caso de que fuera infundada nuestra fuerte inclinación a creer que lo hay, esto mostraría la intención maligna de Dios de engañarnos; pero Dios no puede ser engañador, pues es infinitamente bondadoso, por lo que podemos afirmar que hay un mundo físico (ajeno a nuestra voluntad y a nuestros deseos). ${ }^{11}$ Sin embargo, hay que subrayar lo siguiente: debido a que Dios no es engañador, esto nos garantiza que hay un mundo externo, pero nuestra sensibilidad y nuestros prejuicios, ${ }^{12}$ adquiridos a una temprana edad, nos llevan a tener ideas equivocadas acerca de cómo es este mundo. Para mejorar este conocimiento, la experiencia puede ir puliendo las asperezas de nuestra visión y nos permitirá precisar cada vez más, por así decir, los "contornos" de ese mundo, del que nos dan señales las ideas, pero del que nunca se puede tener la completa certeza.

Ciertamente Descartes no está dispuesto a mantener una tesis representacionista de semejanza. Más bien, su propuesta es la de apegarse a la analogía de signo-significado y sostener que la garantía divina será la que avale la relación entre mis ideas adventicias y un correlato objetivo externo,

$10 \mathrm{Cfr}$. la nota anterior.

11 Así, en la Meditaciones ([9] VII, p. 75 (líneas 5-15); IX, 59 in fine; traduzco del francés), Descartes nos dice:

"Y, ciertamente, al considerar las ideas de todas las cualidades que se presentaban a mi pensamiento y que eran las únicas de las que, propia e inmediatamente tenía una sensación, no carecía de razón que yo creyese tener la sensación de cosas por completo diferentes de mi pensamiento, a saber, cuerpos, de los que procedían estas ideas, pues yo experirmentaba que, sin que se requiriese mi consentimento, ellas se presentaban ante él [mi pensamiento], dẹ tal manera, que yo no podía tener la sensación de ningún objeto, por mucho que lo desease, si el mismo no se encontraba presente ante el órgano de uno de mis sentidos y para nada radicaba en mi poder no tener la sensación del mismo si éste se encontraba presente."

A pesar de que la propuesta final de Descartes será más matizada que ésta que nos ofrece ahora, la creencia esencial queda en pie: hay algo "éxterno" que me produce ciertas ideas y los casos de engaño serán, más bien, porque me apresuro a formular juicios antes de haber analizado adecuadamente la situación. Cfr. la continuación del discurso anterior, en [9] IX, 60 en donde, por ejemplo, podemos leer lo siguiente:

"Pero ahora que comienzo a conocerme mejor a mí mismo y a descubrir más claramente al autor de mi origen, no pienso, en verdad, que temerariamente deba admitir todas las cosas que parecen enseñarnos los sentidos; pero, tampoco pienso que, en general, deba ponerlas todas en duda."

12 Quizás, respecto a esto, podemos aceptar la observación de Descartes de que, en general nuestro entorno (familiar, social, cultural), nos ha dejado huellas (prejuicios) que es difícil hacer de lado; pero, aquí cabe formular la pregunta, y, si los dejamos de lado, ¿con qué los vamos a sustituir? Descartes nos propone hacerlo con el prejuicio cientificista. 
seguramente diferente de éstas. Así no se hace necesaria la postulación de una relación causal mecánica entre un mundo externo, material, mi cuerpo y el espíritu que es el que percibe. Lo que habría que postular, simplemente, sería una acción de Dios quien, a la manera ocasionalista, se serviría de los cuerpos materiales que él creó para provocar ideas que, para mí, fueran signos de dichos objetos.

Es claro que Descartes está obligado a mantener que los cuerpos tienen las propiedades que les pertenecen en tanto seres extensos pero, dadas las peculiaridades de nuestros órganos sensoriales, Dios nos presenta un mundo dotado de cualidades sensibles, propias de cada uno de nuestros sentidos, para que el mundo se nos muestre de tal manera que podamos enfrentarnos a él, conocerlo sensorialmente y evitar peligros y situaciones que puedan dañarnos. ${ }^{13}$ Por otra parte, el mundo sensible nos permite enfrentarnos a los casos particulares, lo cual resultaría imposible si sólo tuviésemos una relación teórica general (conocimiento de universales) que se derivase, únicamente, de los teoremas y propuestas matemáticos y, en especial, geométricos. Dicho en términos que, más tarde, usará Malebranche, Dios impone las sensaciones en nuestro espíritu para mostrarnos que las cosas existen.

Una última, muy alabada doctrina cartesiana, de importancia para mi análisis, es su llamada homogeneización del universo. Con esta propuesta, al ser la extensión el atributo esencial de la materia, serán las mismas leyes geométricas las que rijan siempre que haya cuerpos, a diferencia de lo que sucedía en el cosmos aristotélico. Lo que pasa, por otra parte, es que el universo cartesiano se convierte, de esta manera, en una monótona extensión sin relieves cualitativos. Con Descartes pasamos, entonces, del exceso cualitativo de la física aristotélica, a la pura consideración abstracta, matemática, de la materia.

Lo que parece claro, hasta aquí, es que Descartes, además de haber postulado y defendido un dualismo metafísico, también generó un dualismo categorial en donde, por un lado, se tienen las características cuantitativas

13 En [9], pp. 64-65, Descartes nos dice algo que se aplica, a lo que aquí comentamos del texto principal, además de que sirve para ampliar la nota anterior:

'Y, en efecto, por el hecho de que tengo la sensación de diferentes tipos de colores, olores, sabores, sonidos, de calor, dureza, etc., correctamente [recte concludo] concluyo que, en los cuerpos de los que provienen todas estas diversas percepciones de los sentidos, hay algunas variedades que les corresponden aun cuando, quizás, estas variedades no les sean, en efecto, para nada similares; asimismo, de entre todas estas diversas percepciones de los sentidos, algunas que me son agradables y otras que me son desagradables, puedo extraer una consecuencia totalmente cierta, esto es, que mi cuerpo (o, más bien, yo mismo todo entero, en tanto que estoy compuesto de cuerpo y de alma) puede recibir diversas comodidades o incomodidades de los otros cuerpos que lo rodean." 
$y$, por el otro, las cualitativas, sin que haya una posible unidad entre ellas, ya que, desde cierta perspectiva (la de nuestra relación con el mundo sensible) remite las cualitativas a lo espiritual (esto es, no son propiedades de los objetos materiales) y las cuantitativas a lo material (esto es, son propiedades de la extensión en tanto que es materia o, dicho de otra manera, se trata, al hablar de la física, de considerar la matemática aplicada); o bien, desde la perspectiva de las ideas, las ideas de cualidades están en el plano de las ideas adventicias (esto es, tienen una situación precaria, en tanto que nos presentan el mundo exterior, material), a diferencia de las geométricomatemáticas que se encuentran en el alto nivel de las ideas innatas (las que nos proporcionarán ideas claras y distintas, esto es, de ellas surgirán los juicios cuya verdad será necesaria). Pero entonces, iserá posible que entren en contacto los aspectos cualitativos y cuantitativos, tan tajantemente separados por Descartes?

\section{2d. Extensión, homogeneidad y espacio vacío}

Et plane assentior Hugenio (cujus in rebus naturalibus et mathematicis magna apud me est opinio), essdem esse loci vacui et solius extensionis conceptum; nec meo judicio ipsa mobilitas aut $\alpha \dot{\alpha} \tau \imath \tau \check{v} \pi i ́ \alpha$, ex sola extensione intelligi potest, sed ex subjecto extensionis, a quo non constituatur tantum locus, sed et impleatur. ${ }^{14}$

G.W. Leibniz

14

El texto, traducido, dice:

"Y estoy completamente de acuerdo con Huygens (cuyas opiniones, en física y en matemáticas, valoro mucho), para quien, el concepto de lugar vacío y el de mera extensión son el mismo y,

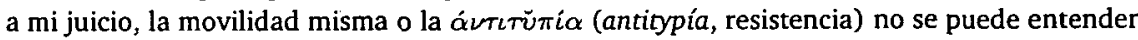
a partir de la mera extensión, sino a partir del sujeto de la extensión, que no constituye sólo el lugar sino que, además, lo llena." (En [18] NV, pp. 364-365; sigo la versión de Olaso, en $\langle 10\rangle$, p. 430). Leibniz presenta la propuesta anterior en, al menos, dos lugares más según lo señala Olaso en loc. cit., n. 33. Aquí me interesa citar un amplio pasaje de su breve escrito "Remarques sur la perception réelle \& substantielle du corps \& du sang de nôtre Seigneur" ("Notas sobre la percepción real y sustancial del cuerpo y de la sangre de nuestro Señor"), del que no tenemos fecha de publicación, en el que señala posibles conclusiones, contrarias a la religión, que se pueden obtener de la propuesta cartesiana de que la materia es esencialmente extensión. En el escrito mencionado, distribuido en secciones numeradas, Leibniz señala lo siguiente:

"7. Pasemos pues, al examen del cuerpo. Muchos toman como un hecho que no conocen sino dos atributos, el pensamiento y la extensión, y dicen que el pensamiento constituye el espíritu y que la extensión constituye el cuerpo. Si esto fuese así seguramente habría una contradicción [il seroit très sur qu'il y auroit implication de contradiction] al decir que un cuerpo o su sustancia está unida inmediatamente a alguna otra sustancia alejada.

8. Pero, también se seguirá que Dios no podría hacer actuar los cuerpos in distans, ni hacerlos pasar a través de otro cuerpo, etc., lo cual parece aventurado. 
Lo que sucede en un mundo material, como el cartesiano, con lo que hasta ahora hemos dicho, podemos expresarlo de la siguiente manera: las partículas de materia, en este mundo (en caso de que pudiera haberlas), no podrán distinguirse, unas de otras, por algún rasgo cualitativo; las partículas serán diferentes solo numero. Descartes, al proponer su universo extenso y homogéneo (no introduzcamos la pregunta acerca de si es o no infinito, para evitarnos considerar problemas extras), se enfrenta a una situación similar a la que tuvieron ante sí los proponentes de un espacio vacío indefinida o infinitamente extenso. Sin embargo, los defensores renacentistas y modernos del espacio vacío (pienso en Patrizi, von Guericke, Gassendi, More, Raphson, entre otros y, ciertamente, en Newton), veían sin sobresalto las propiedades de un espacio vacío, infinito, homogéneo, isotrópico, etc. propiedades que, sin embargo, a Descartes le surgirán como problemáticas en una extensión, con esas cualidades, aunque, ahora, supuestamente, plena de materia.

En un pleno material, homogéneo (isotrópico), como el cartesiano, con la extensión como única propiedad de ese continuo material, no habrá forma de distinguir una porción del mismo de otra, ya que, debido a la homogeneidad señalada, no hay propiedades no métricas que nos permitan llevar a cabo esta distinción, esto es, no podremos hablar de partes distintas unas de

9. Cuanto más en la medida en que eso no se apoya sino en hipótesis por completo precarias o arbitrarias; pues no es verdad, no se ha probado, incluso está alejado del sentir de la Filosofía antigua, que la naturaleza del cuerpo consista en la extensión.

10. El señor Huygens decía, muy bien, que la idea que algunos se forman del cuerpo es, precisamente, la que él tiene del vacío.

11. Por el contrario es fácil hacer ver que, con sólo la noción de la extensión, no se podrían explicar ni la fuerza, ni las leyes del movimiento, ni la inercia natural del cuerpo, ni muchos otros fenómenos.

13. Ahora bien, lo que en el cuerpo es continuo y repetido es, propiamente, la resistencia, sin la cual no habría cuerpo alguno, sino sólo un espacio vacío, incapaz de cambio." (En [17], pp. 30-31)

Pues, así conforme a Lebniz, la física-geométrica de Descartes, tal como aquél la interpreta, carece de los elementos necesarios para explicar muchos de los fenómenos de los que debería dar cuenta. La propuesta geométrica, por sí sola, no permitiría distinguir, según lo señalo en el texto principal, el pleno cartesiano del espacio vacío. Ésta es la intuición que Leibniz le atribuye a Huygens; entonces, no es por medios geométricos como se podrá explicar el movimiento y, por esto, Descartes (también lo propone Gassendi) hace que Dios lo introduzca al momento de crear la materia; por otra parte, Lebniz también se queja de que Descartes no tiene manera de explicar cómo se forman cuerpos en su sistema, esto es, no hay manera de explicar por qué razón los corpúsculos de materia han de permanecer unidos (esto es, en reposo relativo) para formar un cuerpo, ya que no hay fuerza alguna de la que se eche mano para estos efectos.

Igualmente, en [16], p. 42, había señalado la opinión de Huygens con respecto a la identidad entre la materia puramente geométrica y el espacio vacio. 
otras ya que, primero, no podemos distinguir una de otra porción de materia y, ya que ésta llena cualquier espacio, el que sea, no es posible separar una de otra porción pues, primero, la plenitud impediría la separación pero, por otra parte, la homogeneidad no nos permitiría distinguir algo diferente entre las supuestas porciones separadas, que nos mostrara la distancia entre dos partes que no son distintas una de otra y, por esto mismo, tampoco podremos hablar de movimiento, como cambio de lugar, ya que no hay lugares distintos o, dicho de otra manera, cualquier lugar es igual a cualquier otro. Pero, no sólo es por esto por lo que no puede haber movimiento sino que, como lo señala Leibniz, para que algo extenso se pueda mover, no sólo ese algo debe llevar consigo su propio espacio, sino que, además, debe haber un espacio independiente de cualquier objeto material, a lo largo, ancho y profundo del cual se pueda mover. ${ }^{15}$

\section{2e. El universo y su constitución en términos de tres tipos de elementos}

Aquí quiero detenerme a considerar el siguiente problema: el mundo, según nos dice Descartes, io creó Dios como un continuum material, constituido por partículas (indivisibles, por imposición, aun cuando no por naturaleza, dotadas de movimiento y agrupadas en tres tipos de elementos, en donde las partículas del primero son las más pequeñas y veloces, las del segundo mantienen un tamaño y una velocidad intermedios y las del tercero son las más masivas y lentas, de tal manera que, entre ellas, se señala una fuerte diferencia cualitativa; pero, dado que la propiedad esencial de la materia es la extensión, todas las partículas tienen la misma naturaleza, pero esta homogeneidad parece estar en entredicho cuando Descartes sostiene que, según su diferente grado de masividad, las partículas se comportan de manera diferente y que, por otra parte, cada partícula permanece fiel al elemento al que pertenece (esto es así según Descartes, por la inmutable voluntad de Dios, quien no modifica su creación una vez realizada), ${ }^{16} \sin$

15 Cfr. supra, epígrafe a esta sección y nn. 6 y 14.

16 Lo que esto quiere decir, para Descartes, es como una especie de regla gramatical a la Wittgenstein, en el sentido de que, por más cambios que se perciban en el mundo, ninguno se va a considerar como "un cambio en la voluntad de Dios", sino que será un cambio en la naturaleza; así Descartes nos dice (en [7] §VII, p. 37):

"me sirvo de esa palabra [Naturaleza] para referirme a la Materia misma en tanto que la considero con todas las cualidades que le he atribuido, comprendidas todas conjuntamente, y bajo la condición de que Dios continúe conservándola de la misma manera como la ha creado. Pues sólo de esto, de que la conserve así, se sigue necesariamente que debe sufrir múltiples cambios en sus partes, los que, según me parece, al no poder atribuirse, propiamente, a la acción de Dios, porque ésta para nada cambia, yo los atribuyo a la Naturaleza; y las reglas conforme a las que se hacen estos cambios, las denomino Leyes de la Naturaleza". 
que haya un "decaimiento" o una "elevación" de partículas de uno a otro nivel. Así pues, lo que finalmente parece concluirse de esto es que, a pesar de las declaraciones en contra, Descartes mantiene la heterogeneidad del universo aristotélico, aun cuando ahora sea en el nivel de sus elementos, los que no están sujetos a la corrupción; esto es, a partir de su origen por creación divina, siempre permanecen los mismos, sin alteración. Pero, si esto es así, el universo cartesiano no es homogéneo, sino que las partículas de los diversos elementos tienen comportamientos que no dependen, para nada, de sus propiedades geométricas, sino de algunas propiedades ocultas (dadas por Dios), que son las que las hacen ser lo que son.

Ahora, de las consideraciones anteriores, podemos plantearnos los siguientes problemas, acerca de nuestra visión del mundo, en términos de cualidades secundarias: ¿cómo entenderemos la relación semántica, signosignificante, si no hay una relación necesaria o que nosotros podamos establecer, entre aspectos cualitativos y aspectos geométricos? o bien, ¿cómo podemos entender la presentación de objetos diferenciados si, en el monótono continuo cartesiano no podemos encontrar ninguna distinción asi? Una pregunta cuya respuesta siempre me ha causado problemas es ¿cómo relacionamos la extensión inteligible, de la cual tengo una idea innata, con la extensión sensorial, cualitativa, que nuestros sentidos nos presentan?

Además, puesto que ese mundo material, científico, no es visible, tangible, etc. ¿en qué se distingue, finalmente, de la pura nada o, al menos, del espacio puro que propusieran los pensadores antes mencionados? Pero, por otra parte, si se puede distinguir del puro espacio vacío, será porque el universo cartesiano no es homogéneo, no se tiene la existencia de un solo tipo de materia, ya que los tres elementos cartesianos son tanto cuantitativa como cualitativamente diferentes y esto último debido a que poseen cualidades ocultas o demasiado ad hoc, que Descartes les atribuyó para que se comportaran de la manera por él requerida. Así pues, en el universo cartesiano, de ninguna manera se ha logrado, por completo, la muy alabada y supuesta emancipación del feudo aristotélico (no se ha logrado la homogeneización del universo) ni se han hecho de lado las fantasías mágicas renacentistas. Pero, por otra parte, en caso de que se hubiera logrado la homogeneización total, el resultado habría sido la pérdida completa de distinciones.

De las tesis cartesianas se derivan, entre otras, las siguientes reacciones que aquí me interesa destacar.

\section{John Locke (1632-1704)}

Las ideas del mundo sensible, para Locke, son efecto de un no sé qué que las produce y, para paliar un tanto el elemento escéptico en la propuesta 
cartesiana, se anima a decir que las ideas de las cualidades primarias se asemejan a las cualidades que representan (con una semejanza mayor que la que, en muchos casos, se pueda dar entre el signo y lo significado), lo cual introduce un misterio que está ausente de la propuesta de Descartes, pues la tesis de parecido, entre dos entidades (material y espiritual) que sólo tienen en común el hecho de existir y durar, requiere de una explicación mayor que la más cauta propuesta de Cartesio.

Ciertamente, Locke sigue manteniendo, de manera completa, la distinción cualidades primarias-cualidades secundarias y, con ella, la fuerte diferencia óntica entre ellas. Las primarias son propiedades de los cuerpos; las secundarias las causan poderes que tienen los cuerpos, gracias a sus cualidades primarias, de producir en nosotros las sensaciones ligadas, de manera específica, a los diversos sentidos; las cualidades primarias, en cambio, son sensibles comunes a la vista y al tacto. Finalmente, la fuerte diferencia óntica, introduce una diferencia, también, en el estatus epistémico de nuestras ideas: las ideas de cualidades primarias tienen una jerarquía mayor, en tanto que, como lo señalé, son las que mantienen una semejanza con el objeto; lo que no sucede con las secundarias, que surgen de la interacción sujeto-objeto.

Por otra parte, en la propuesta lockeana se mantiene el dualismo, se propone la relación causal mecánica directa entre las partículas no sensibles que emiten los objetos externos y las terminaciones nerviosas de nuestros cuerpos, aun cuando se propone, como un misterio (de manera muy clara, en [21], $\S 10$, escrito de Locke, de publicación póstuma) el paso del aspecto mecánico, de movimiento y choque de los espíritus animales, a la aparición de la idea para presentar el objeto a la conciencia.

También en otra de sus obras póstumas [20], Locke expresa una tesis que pudiera entrar en conflicto con otras tesis publicadas, a saber, en la obra citada nos dice que la figura visual sólo se percibe debido a la limitación cromática, es decir, sólo porque vemos límites (cromáticos) entre objetos es que podemos detectar sus formas, esto es, gracias a las que no son cualidades de ellos, porque las cualidades secundarias nos las muestran, es que llegamos a conocer las cualidades primarias de los objetos, es decir, sus cualidades reales. ${ }^{17}$

17 Según lo señalé, en [20], cap. XI, "Sobre los cinco sentidos" al finalizar el §1, 'Sobre la vista', Locke escribió, como en pasant, lo siguiente:

"Besides colour, we are supposed to see figure; but, in truth, that which we perceive when we see figure, as perceivable by sight is nothing but the termination of colour."

[Además del color, se supone que vemos la figura; pero, en verdad, lo que percibimos cuando vemos la figura, en tanto que perceptible por los ojos, no es más que la terminación del color.] 


\section{Nicolas Malebranche (1638-1715)}

Para el filósofo oratoriano, la materia es por completo ininteligible para nuestro espiritu, por lo que nunca podremos conocer ninguna de sus propiedades; el mundo que conocemos es un mundo inteligible, lo que para el oratoriano quiere decir que se trata de un mundo de ideas y éstas las vemos en Dios, aun cuando las mismas, de alguna manera, aluden al sustrato material. Para no entrar demasiado en problemas de interpretación de las propuestas malebranchianas, podemos decir que el mundo del que tenemos conocimiento es el que se nos da de manera inmediata, un mundo de ideas que Dios nos presenta y de sensaciones que Dios impone en nuestros espíritus. La materia, sea ésta lo que sea, Dios la usa ("¿por qué necesita de un instrumento para actuar?", preguntará Berkeley irónicamente ${ }^{18}$ ) como

18 En [5] hay una larga discusión entre Hylas y Filonús con respecto a cómo interpretar lo que sea la materia, desde la perspectiva instrumentalista/ocasionalista (cfr. el diálogo 2; pp. 213-226); a medio camino de la discusión (en op. cit. pp. 217-218) Berkeley escribió lo siguiente:

"HYlAS: Pero, aun cuando la materia pueda no ser una causa, empero, ¿qué es lo que impide que sea un instrumento que le sirva al agente supremo en la producción de nuestras ideas?

FLonús: Un instrumento, ¿dices? Pero, explícame, ¿cuáles serán la figura, los resortes, las ruedas y movimientos de ese instrumento?

HyLAs: De ellos nada pretendo determinar, pues tanto su sustancia como sus cualidades me son por completo desconocidas.

Filonús: ¿Cómo? Entonces, ¿mantienes la opinión de que está hecho de partes desconocidas, que tiene movimientos y forma desconocidos?

HYLAS: No creo que tenga figura o movimiento alguno, pues ya estoy convencido de que ninguna cualidad sensible puede existir en una sustancia no percipiente.

Fuonús: Pero, ¿qué noción es posible forjar de un instrumento carente de cualesquiera cualidades sensibles e incluso de la extensión misma?

HyLas: Yo no pretendo tener noción alguna de él.

Filonús: Y, ¿qué razón tienes para pensar que exista este algo desconocido, inconcebible? ¿Es que imaginas que Dios no puede actuar tanto con él como sin él o que, por experiencia, tú apelas a alguna cosa así cuando formas ideas en tu mente?"

Un poco más adelante (ibid. pp. 219-220), una propuesta similar surge, ahora, con la mención expresa del ocasionalismo:

"Hyıas: No mantendré más que la materia es un instrumento. Sin embargo, tampoco me gustaría que se supusiese que he renunciado a su existencia. Sin embargo, a pesar de todo lo que se ha dicho, la misma aún puede ser una ocasión.

FiLonús: ¿Cuántas formas va a tomar tu materia? $\mathrm{O}$, ¿cuán a menudo debe probarse que no existe antes de que estés dispuesto a separarte de ella? Pero, para no decir más (aun cuando, conforme a todas las reglas de la discusión, yo podría justamente culparte de cambiar con harta frecuencia el significado del término principal) me interesaría saber, qué es lo que quieres decir al afirmar que la materia es una ocasión, tras haber ya negado que es una causa. Y, cuando 
la ocasión para producir en nosotros la creencia de que lo que percibimos existe.

Como vemos, Malebranche rechaza toda sugerencia con respecto a cualquier atisbo de conocimiento inmediato (directo) de lo que sea el mundo material. Lo que conocemos es lo que percibimos directamente, sin más, aun cuando concede que queda un residuo de realidad, que es por completo incognoscible (¿cómo puede asegurar esto?).

Algo importante que aquí hay que destacar es que, también Malebranche, señala que son las cualidades secundarias las que nos permiten detectar las cualidades primarias en el mundo, ya que es mediante la limitación cromática como nos damos cuenta de la forma de los objetos. Malebranche dejó registrada esta propuesta en diferentes partes de su obra; por ejemplo, en sus Conversations chrétiennes, además de hablarnos de las cualidades secundarias (los colores, en particular), como presentadoras del mundo sensible, también nos habla del mundo puramente inteligible, en su peculiar versión de la, "visión en Dios" de las ideas o representantes de las cualidades primarias:

hayas mostrado en qué sentido entiendes ocasión, te pido que, de inmediato, me muestres qué es lo que te indujo a creer que hay una ocasión tal para nuestras ideas.

HyLAs: Con respecto a lo primero, con ocasión, me refiero a un ser no activo, no pensante, ante cuya presencia Dios despierta ideas en nuestras mentes.

FiLonús: $Y$, ¿cuál puede ser la naturaleza de ese ser no activo, no pensante?

HYLAs: No sé nada de su naturaleza.

Filonús: Pasemos, pues, a lo segundo y asigna alguna razón por la que hayamos de darle alguna existencia a esa cosa desconocida, no activa, no pensante.

HYLAS: Cuando vemos ideas producidas en nuestra mente, de manera ordenada y constante, es natural que pensemos que tienen ocasiones fijas y regulares, ante cuya presencia son producidas.

Filonús: Entonces reconoces que sólo Dios es la causa de nuestras ideas y que Él las causa ante la presencia de esa ocasiones.

HyLAs: Ésa es mi opinión.

Filonús: Sin duda, esas cosas que dices que están presentes ante Dios, Él las percibe.

HyLAs: Ciertamente; de otra manera, no podrían ser, para él, una ocasión de actuar.

Filonús: Para no insistir, ahora, en que le des sentido a esta hipótesis o que respondas todas las extrañas cuestiones y dificultades que ella origina, sólo te pregunto si la sabiduría y el poder de Dios no dan cuenta suficiente del orden y la regularidad observables en la serie de nuestras ideas o en el proceso de la naturaleza y si, suponer que una sustancia no pensante lo ha influido, dirigido o convencido acerca de cuándo y de qué tiene que hacer, ¿no rebajaría esos atributos? Y, finalmente, ien qué te beneficiaría que yo te concediese todo lo que pides? pues no es fácil concebir cómo la existencia externa o absoluta de una sustancia no pensante, distinta de su ser percibida, puede inferirse de que yo te conceda que hay ciertas cosas percibidas por la mente de Dios las que, para Él, son la ocasión de producir ideas en nosotros." 
He aquí, pues, mi razonamiento. No es sino el color el que hace visibles los objetos, vemos y distinguimos la diversidad de los objetos únicamente por la variedad de los colores. Ahora bien, cuando vemos los cuerpos, es la idea de la extensión la que nos modifica con diversas sensaciones de color y estaréis de acuerdo en que esta idea no se encuentra sino en Dios. Así pues, es evidente que vemos en Dios toda esta variedad de cuerpos de la que tenemos sensaciones $\tan$ diferentes, puesto que es cierto que para nada vemos los objetos en sí mismos... ([23] §iii)

Lo que es muy curioso constatar en esta propuesta que, en lo esencial, sigue muy de cerca la tesis cartesiana, es que es la porción menos confiable de nuestros datos perceptuales la que nos "presenta" el llamado "mundo real", esto debería propiciar una consideración menos negativa a estos detractores del conocimiento sensible, ya que parece que podríamos concluir que, sin la presentación sensorial, o bien nada conoceríamos o estaríamos situados en un nivel óntico superior al de los seres humanos. Algo que podemos concluir de esta constatación es que la dependencia que Locke, en su Ensayo, parecía otorgarles a las cualidades secundarias con respecto a las primarias, se invierte, al menos epistémicamente; así, podemos decir que las cualidades secundarias son condiciones necesarias para la percepción, al menos, de los seres humanos; ahora podríamos preguntar, ¿por qué hémos de suponer que las cualidades primarias son semejantes a lo que se nos presenta en los perceptos y tienen una preeminencia óntica con respecto a las secundarias?

Tanto en el caso de Locke, como en el de Malebranche, la analogía cartesiana ha resultado inoperante: para Locke era necesaria mayor precisión acerca de la representatividad de la idea con respecto a la supuesta realidad material, aun cuando señala que la causa de las ideas era un no sé qué. Malebranche es más tajante en su rechazo de la relación ideas-mundo material: no hay relación inteligible entre estas dos entidades tan por completo separadas; esto es, no hay relación posible.

La conclusión que parece seguirse de las propuestas anteriores es que no podemos tener conocimiento inteligible del mundo real, esto es, simplemente no podemos tener conocimiento del mundo.

\section{George Berkeley (1685-1753)}

Este autor tiene problemas para aceptar tesis que privan el mundo real de los atributos que nos permiten distinguir los objetos y esto sólo por el hecho de que son aspectos cualitativos y no cuantitativos de la realidad.

El futuro obispo de Cloyne está convencido de que son las cualidades secundarias las que nos permiten entrar en contacto con el mundo sensible 
o, dicho de otra manera, es por medio de las llamadas cualidades secundarias como se nos presentan las primarias (como ya lo habían señalado tanto Locke como Malebranche) y, si esto es así y, por otra parte, es absurdo suponer la existencia de una sustancia material, además de las ideas sensibles, entonces, ónticamente, están a la par las cualidades primarias y las secundarias y las variaciones que sufran las llamadas cualidades secundarias obviamente se reflejarán en las primarias. Epistémicamente, entonces, no hay diferencia en el estatus de las ideas, en tanto que primarias o secundarias. Por otra parte, al rechazar, por absurda, la posibilidad de sostener la existencia de un sustrato material, el mundo de Berkeley se hace patente, al perceptor, de manera plena: lo que percibimos es lo que hay y no tenemos que suponer la existencia de algo más, por siempre oculto a nuestra percepción.

Berkeley propone, pues, que el mundo presente ante nosotros es el mundo real. Hay que tener en cuenta que las ideas berkeleyanas no son modificaciones del espíritu; las ideas berkeleyanas, con respecto al mundo sensible, tienen el mismo estatus cartesiano de ser ajenas a mi voluntad. El mundo de Berkeley, así, es un mundo inteligible sólo en tanto que está presente a una mente. Conforme a la famosa frase de Berkeley ( 3 diálogos, diál. 3 , p. 244) él no convirtió las cosas en ideas, sino las ideas en cosas. En la concepción berkeleyana, no hay dos mundos, el mundo presente ante mí y el mundo material, corpuscular, "detrás" de las ideas. Sólo hay el mundo presente ante nosotros y éste lo conocemos de manera inmediata; no hay que postular ningún tipo de acción a distancia con una causa misteriosa.

La propueșta berkeleyana se contenta con el ocasionalismo cartesiano que hereda directamente de Malebranche, pero sin el oscuro elemento de la materia, molesta carga cartesiana, con la que lidiaron, sin mucho éxito, tanto Locke como Malebranche.

Con Berkeley aceptamos el mundo sensible tal como éste se nos da, es decir, unidos los aspectos cualitativos y cuantitativos. Berkeley se cuida mucho de no separarlos; lo que él hace, más bien, es señalar que hay aspectos varios del mundo que se presentan necesariamente unidos, debido a las condiciones mismas de los órganos de percepción, esto es, desde Aristóteles sabemos que hay cualidades propias de cada sentido y, así, sólo la vista percibe luz y colores; pero, ¿sería posible que se percibieran sin extensión? Ciertamen: te, una de las lecciones que Berkeley aprende de Locke y de Malebranche es que sin cualidades secundarias no es posible percibir las primarias y la adición que Berkeley propone es que sin la esencial cualidad cartesiana de la extensión no le es posible, a la vista, percibir sus objetos propios, a saber, luz y colores, así como, sin extensión, no le sería posible al tacto percibir sus objetos propios, las texturas táctiles. Aquí surge, también, una oposición fuerte a las propuestas cartesianas o, al menos, a la interpretación (que yo 
considero posible) que de las mismas hace Malebranche y esto es, según lo señalé páginas atrás, que, conforme a la tesis de Descartes de que las cualidades secundarias o sensibles son modificaciones de nuestro espíritu, las mismas, conforme lo señala explícitamente Malebranche, deben ser inextensas, pues bien sabemos que la extensión no es una característica propia del espíritu. Ciertamente ésta no es una conclusión que quiera o pueda aceptar Berkeley, pues una cualidad inextensa, para la vista o el tacto, no podría ser una cualidad sensible, por la simple razón de que nuestros sentidos no la registrarian. Lo que Berkeley mantiene, entonces, es que las extensiones (visual y táctil), son condiciones necesarias de la presencia, ante nuestros sentidos (vista y tacto), de las características definitorias del mundo sensible. Dicho de otra manera, los aspectos sensibles, cualitativos, del universo (las cualidades propias de los sentidos), no pueden ser percibidas si las mismas no se presentan engalanando el tapiz (extenso) del universo. Así pues, lo que sostiene Berkeley es que las ideas no son modos del espíritu y, por esto, los colores pueden ser extensos, así como pueden y deben tener extensión las texturas tangibles y lo que Berkeley señala es que el espíritu capta las ideas, precisamente, como ideas, esto es, como algo ajeno que el espíritu comprende. Lo que está implícito en todo lo anterịor, es que Berkeley convierte la extensión cromática en un objeto sólo visual y la extensión táctil en un objeto sólo del tacto. En algún sentido, no podemos hablar, dentro del contexto berkeleyano, de una y la misma extensión, en un caso en modalidad cromática y en otro en modalidad táctil, sino, más bien, como dos objetos (o ideas) complejos diferentes, uno, la extensión-lúmino-cromática, como el objeto propio de la vista y otro, la extensión-texturo-táctil, como el objeto propio del tacto; dos objetos por completo diferentes, aun cuando fuertemente relacionados en nuestra experiencia del mundo: normalmente (aunque no siempre) a ciertos datos visuales les corresponden ciertos datos táctiles. Sin embargo, aquí Berkeley se enfrentará a serios problemas para lograr configurar objetos físicos normales, esto es, tales como los suponemos en nuestros momentos no filosóficos.

\section{Conclusiones}

La tajante separación cartesiana entre espíritu y materia lleva aparejada otra distinción tajànte entre modos (matemáticos, cuantitativos), propios del cuerpo, esto es, de la extensión y modos (sensibles, cualitativos), propios del espíritu, esto es, de lo inextenso. En este escrito, he alegado que la caracterización de los cuerpos que, en términos puramente de extensión, ofrece Descartes, hace que su mundo material no se distinga del espacio vacío, de un espacio carente de distinciones cualitativas. Esto nos lleva a una conclusión totalmente opuesta a los deseos y tesis cartesianos, esto 
es, podemos ver mi alegato como una reductio ad absurdum de la tesis de Descartes. Por otra parte, si se alega que el mundo científico cartesiano es homogéneo pero no isotrópico, lo que sostengo es que esto último se alcanza sólo si se pone en entredicho la homogeneización, introduciendo la doctrina de los elementos, lo que produce una distinción cualitativa entre elementos simples (no sujetos a la corrupción) separados en tres tipos y, entre éstos y los seres compuestos, sujetos a la generación y la corrupción. De los elementos simples, no corruptibles, se puede alegar que se mantienen así por estar dotados de cualidades ocultas. Finalmente, quiero subrayar que el problema que tiene nuestro autor para poner en contacto ideas y mundo material, se duplica, pues se apoya en el intento de poner en contacto cualidades primarias (cuantitativas) con cualidades secundarias (cualitativas).

Los filósofos posteriores, entre ellos Locke y Malebranche, señalan que hay una fuerte unidad, en idea, entre las cualidades primarias y las secundarias, pues estas últimas presentan, a las primeras, pero ellos no se animaron a eliminar la sustancia material, lo que les sigue originando problemas similares a los que tiene Descartes.

No será sino con la propuesta de Berkeley, de eliminar la sustancia material (desconocida e incognoscible) y de poner a la par las cualidades primarias y las cualidades secundarias, como aspectos inseparables de las ideas (esto es, ya sin la connotación de dependencia-independencia que les otorgaban los autores anteriores), que se obtiene una visión unificada del mundo sensible pues, insisto nuevamente, elimina el mito de la sustancia material que quedaba fuera del alcance cognoscitivo del ser humano. Esto es, Berkeley propone una homogeneización por encima de la ya propuesta por Descartes, aunque a este último, dentro de los límites del problema que a mí me ha ocupado, y haciendo de lado ciertas limitaciones en su homogeneización, no se le podrá negar la gloria de haber originado una vía de reflexión que impulsaría el avance de la ciencia, contraria a las doctrinas establecidas y esto fue lo que hizo surgir una física ajena al patrón cualitativo de la investigación científica aristotélica.

\section{BIBLIOGRAFIA}

Antologías, enciclopedias, obras completas, etcétera

(1) Berkeley, George, The Works of George Berkeley Bishop of Clyone, 2a. ed. (19481957), A.A. Luce y T.E. Jessop (comps.), vols. I-IX, Thomas Nelson and Sons Ltd., Londres, 1964. 
$\langle 2\rangle$ - Comentarios filosóficos. Introducción manuscrita a los Principios del conocimiento humano. Correspondencia con Johnson, selección, traducción, introducción y notas de José Antonio Robles, Instituto de Investigaciones Filosóficas-unam, México, 1989.

(3) Descartes, René, CEuvres, vols. I-XI, Charles Adam y Paul Tannery (comps.), (Obra publicada con la colaboración del Centre National du Livre), Librairie Philosophique J. Vrin, París, 1996.

(4) Diels, H. (comp.), Commentaria in Aristotelem Græca, Berlín, 1882-1909. Los comentarios de Filópono se encuentran en los vols. 13-17.

(5) Galileo Galilei, Discoveries and Opinions of Galileo, traducción, introducción y notas de Stillman Drake.

(6) Koyré, Alexandre, Estudios de historia del pensamiento científico, traducción del francés de Études d'histoire de la pensée scientifique, Gallimard, 1973, Encarnación Pérez Sedeño y Eduardo Bustos (comps.), Siglo XXI editores, México/España/Argentina/Colombia, 2a. ed. en español, 1987.

(7) Leibniz, G.W., Die philosophischen Schriften von G.W. Leibniz, C.I. Gerhardt (comp.), 7 vols., Berlín, 1875-1890. Georg Olms Verlag (reimp.), Hildesheim/Nueva York, 1960-1961.

(8) Locke, John, La conducta (sic) del entendimiento y otros ensayos póstumos, (edición bilingüe), introducción, trạducción y notas de Ángel M. Lorenzo Rodríguez, Ánthropos, editorial del hombre, Madrid, 1992.

(9) Malebranche N., CEuvres complètes, 2a. ed., cnRs y Librairie Philosophique J. Vrin, Paris, 1972-1978, tt. I-XX.

(10) Robles, José Antonio y Carmen Silva (comps.), Obras varias y correspondencia de (y sobre) John Locke, selección, traducción, introducción y notas de José Antonio Robles y Carmen Silva, Publicaciones del departamento de filosofía (Serie clásicos $\Sigma)$, Universidad Autónoma Metropolitana-Iztapalapa, México, 1991.

(11) Sorabji, Richard (comp.), Philoponous, and the Rejection of Aristotelian Science, Cornell University Press, Ithaca, N.Y., 1987.

\section{Obras consultadas}

[1] Aristóteles, Physique, texto establecido y traducido por Henri Carteron, Societé d'éditions "Les belles lettres", París, t. primero (I-IV) 2a. ed., 1952; t. segundo (V-VII) 3a. ed. revisada y corregida, 1961.

[2] Benítez; Laura, El mundo en René Descartes, Instituto de Investigaciones FilosóficasUNAM, México, 1993.

[3] Berkeley, George, Philosophical commentaries, en $\langle 1\rangle$ I, pp. 7-104. Traducido como Comentarios filosóficos, en $\langle 2\rangle$, pp. 19-128.

[4] - A Treatise Concerning the Principles of Human Knowledge (1710), en (1) II, pp. 19-113.

[5] —-, Three Dialogues Between Hylas and Philonus (1713), en 〈1〉 II, pp. 163-263.

[6] Caspar, Max, Kepler (1948, la versión original en alemán), traducido y editado por C. Doris Hellman, con nueva introducción y referencias de Owen Gingerich y citas bibliográficas de Owen Gingerich y Alain Segonds, Dover Publications, Nueva York, 1993. 
[7] Descartes, René, Le monde ou Traité de la lumiere (1664), en 〈3〉 XI, pp. 1-202. Hay traducción al español: El mundo o tratado de la luz, estudio introductorio, traducción y notas de Laura Benítez Grobet, Instituto de Investigaciones Filosóficas-unam, México, 1986.

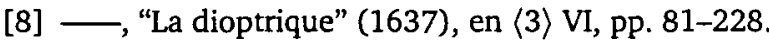

[9] - Meditationes de prima philosophia (1641), en $\langle 3\rangle$ VII, pp. 1-90 y Les meditations metaphysiques (1667), en $\langle 3\rangle$ IX, pp. 1-72.

[10] - Principia philosophia (1644), en 〈3〉 VIII, pp. 1-348 y Principes de la philosophie (1647), en (3) IXb, pp. 1-353 + I-XX (ilustraciones).

[11] Descartes y Leibniz, Sobre los principios de la filosofía, traducción de las partes pertinentes de los Principios de Descartes (1644, latín y 1647, francés) y del ensayo de Leibniz, Animadversiones in partem generalem principiorum cartesianorum $(\mathrm{Ob}$ servaciones críticas sobre la parte general de los principios cartesianos, 1692), y notas de E. López y M. Graña, Biblioteca Hispánica de Filosofía, Gredos, Madrid, 1989.

[12] Furley, David, "Summary of Philoponus' Corollaries on Place and Void", en $\langle 11\rangle$, pp. 130-139.

[13] Galileo Galilei, The Assayer (Il saggiatore; fragmentos). En 〈5), pp. 229-280.

[14] Kenny, Anthony, Descartes. A Study of His Philosophy, Random House, Nueva York, 1968

[15] Koyré, Alexandre, "Gassendi y la ciencia de su tiempo", en 〈6), pp. 306-319.

[16] Leibniz, G.W, "De religione magnorum virorum" (1687-1694), en $\langle 7\rangle$ I, pp. 35-44.

[17] _ - "Remarques sur la perception réelle \& substantielle du corps \& du sang de notre Seigneur", en $\langle 7\rangle$ I, pp. 30-32.

[18] — Animadversiones in partem generalem principiorum cartesianorum (16911697), en $\langle 7\rangle \mathrm{IV}$, pp. 350-392.

- Cfr. supra Descartes y Leibniz.

[19] Locke, John, An Essay Concerning Human Understanding (1690/1700 4a. ed.), editado por y con una introducción de Peter H. Nidditch, Clarendon Press, Oxford, 1975.

[20] -, Nociones de filosofia natural (Elements of Natural Philosophy), en $\langle 8\rangle, \mathrm{pp} .204$ 329 (pares, el texto inglés; impares, el texto castellano).

[21] —-, Examen de la opinión del P. Malebranche de ver todas las cosas en Dios, en $\langle 10\rangle$, pp. 35-81.

- Cfr. Robles, José A. y Carmen Silva (comps.).

[22] Malebranche, N., De la recherche de la verité, oú l'on traite de la nature de l'esprit de l'homme et de l'usage quil' en doit faire pour éviter l'erreur des Sciences (16751676; 6a. ed. 1712), Geneviève Rodis-Lewis; con la propuesta de Henri Gouhier, en $\langle 9\rangle$, tt. I-III.

[23] - Conversations chrétiennes (1702), André Robinet (comp.), en $\langle 9\rangle$, t. IV.

[24] Monroy Nasr, Zuraya, De las Meditaciones a las Pasiones de R. Descartes. (Distinción e interacción substancial.) Tesis de doctorado, unaM, México, 1997.

[25] Williams, Bernard, Descartes: el proyecto de la investigación pura, trad. Laura Benítez [Descartes: The Project of Pure Enquiry, The Harvester Press, 1978], Instituto de Investigaciones Filosóficas-unam, 1995. 